\title{
AUTOMATIZAÇÃO DE UM DESTILADOR D’ÁGUA
}

Carlos A. Neves, Ivano G. R. Gutz e Claudimir L. do Lago*

Departamento de Química Fundamental - Instituto de Química - Universidade de São Paulo - Av. Prof. Lineu Prestes - 748 05508-900 - São Paulo - SP

Recebido em 30/7/97; aceito em 6/11/97

\begin{abstract}
AUTOMATization OF A WATER Distilling APPARATUS. A simple and inexpensive device to automate a water distilling apparatus is shown. It is composed by a magnetic floater placed in the water reservoir and a level control unit, which acts over the heating element circuit. In order to provide water saving, an electromagnetic valve is inserted in the water supply inlet. Some suggestions for the adaptation to other types of equipment are also offered.
\end{abstract}

Keywords: water distilling apparatus; automation.

\section{INTRODUÇÃO}

Sem dúvida alguma, o solvente mais utilizado em um laboratório químico é a água. Esta deve ter pureza adequada e, apesar das possíveis alternativas para se alcançar tal qualidade, a destilação convencional é ainda a maneira mais comum. Embora de funcionamento bastante simples, esta técnica acaba por consumir uma considerável quantia de energia elétrica e água, além de cuidados constantes de uma ou mais pessoas do laboratório que se responsabilizam por sua operação. Assim, dispositivos ou sistemas que otimizem seu funcionamento são sempre bem vindos a um laboratório com um consumo considerável de água destilada.

Nesta nota, descrevemos um sistema que controla o aquecimento e o fluxo de água de alimentação de um destilador, de modo a manter dentro de certos limites o nível de água destilada no reservatório onde é coletada. Este sistema foi implementado com componentes de baixo custo e pode ser facilmente modificado para se adequar aos equipamentos e necessidades de outros laboratórios.

\section{PARTE EXPERIMENTAL}

O destilador automatizado foi um MARCONI modelo MA078, 220V e 3000W. Para tanto, foi necessário fazer uma análise do circuito eletrônico do destilador que controla as resistências de aquecimento. A figura 1 mostra o diagrama de blocos do Circuito Controlador de Potência (CCP) original. De modo simplificado, o CCP possui duas chaves do tipo push button, sendo uma normalmente aberta (NA) para ligar o destilador e outra normalmente fechada (NF) para desligá-lo. Estas chaves não controlam diretamente as resistências, mas sim um tiristor (TRIAC) de potência que executa esta tarefa. Assim, por estas chaves, passa uma pequena corrente quando comparada àquela que aquece as resistências. Para proteção contra superaquecimento, o destilador é equipado com disjuntores térmicos em pontos críticos.

\section{UNIDADE CONTROLADORA DE NÍVEL (UCN)}

A finalidade da UCN é simular as atividades do operador que, baseado no nível de água destilada do reservatório, liga ou desliga o destilador. O nível é acompanhado através de um sistema de bóia e chaves magnéticas (reed switches) que será detalhado na próxima seção.

$\mathrm{O}$ acionamento é feito através da colocação de dois relês em paralelo com as chaves originais da CCP para ligar e desligar o

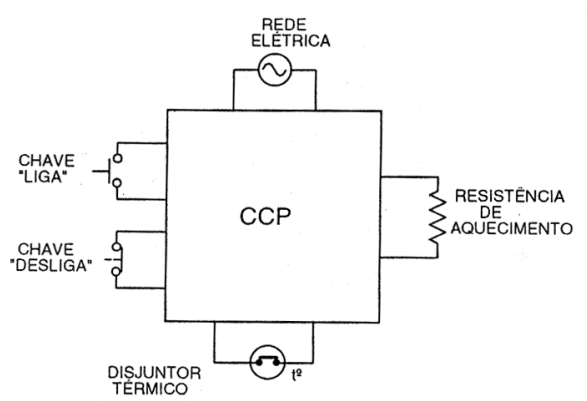

Figura 1. Diagrama simplificado do Circuito Controlador de Potência $(C C P)$.

aquecimento. Como estas chaves são do tipo push button, o acionamento destes relês deve ser feito por um breve período de tempo.

A figura 2 mostra o circuito da UCN, enquanto a figura 3 mostra como este deve ser acoplado ao CCP. O conjunto D1, $\mathrm{R} 1, \mathrm{R} 2, \mathrm{Z1}$, Z2 permite que o capacitor $\mathrm{C} 1$ seja carregado a 9,4 V em, aproximadamente, 12 segundos. Quando RS1 ou RS2 é acionado pela bóia magnética o capacitor $\mathrm{C} 1$ se descarrega acionando RL1 ou RL2, respectivamente, por um período pouco menor que um segundo. RS1 é acionado quando o nível d'água está baixo. Assim, RL1 substitui a função da chave "liga" do CCP. Para tanto, são utilizados os contatos b e c de RL1. Quando o reservatório estiver cheio, RS2 e, por conseguinte, RL2 são acionados, desligando o destilador. Isto é conseguido conectando os terminais a e b de RL2 com os da chave "desliga" do CCP.

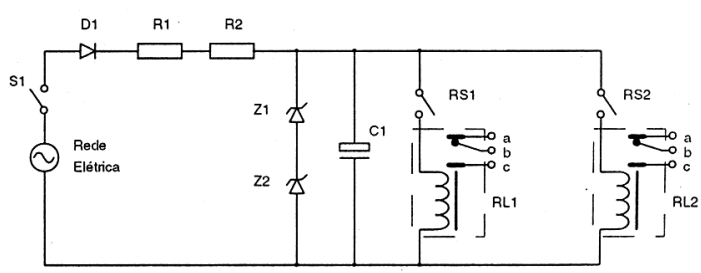

Figura 2. Unidade Controladora de Nível (UCN). Componentes: S1 chave liga/desliga; $R 1$ e $R 2$ - resistores de $39 \mathrm{k} \Omega$ 1/2 W; $C 1$ capacitor eletrolítico de $1000 \mu \mathrm{F} 50 \mathrm{~V} ; \mathrm{D} 1$ - diodo 1 N4007; Z1 e Z2 - diodo zener BZX79C4V7 (4,7 V e $400 \mathrm{~mW}) ; R L 1$ e RL2 - relê Hasco KLT1C12DC12 (1 polo x 2 posições); RS1 e RS2 - chave reed switch Metaltex SM1001. 


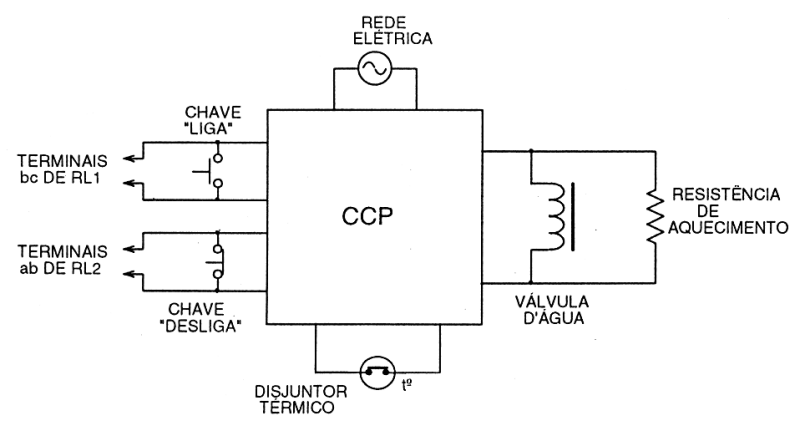

Figura 3. CCP modificado, com a indicação da inclusão da válvula de entrada d'água e terminais dos relês da UCN (figura 2).

\section{SENSOR DE NÍVEL}

A figura 4 mostra o posicionamento do sensor de nível no reservatório d'água. Os reed switches RS1 e RS2 foram colocados em diferentes alturas na parte externa e indicam, respectivamente, os níveis d'água quando o destilador deve ser acionado e quando o tanque está cheio. Na face interna do reservatório, foi colocado um tubo de vidro aberto em suas extremidades, servindo de guia para a bóia magnética que aciona estes reed switches.

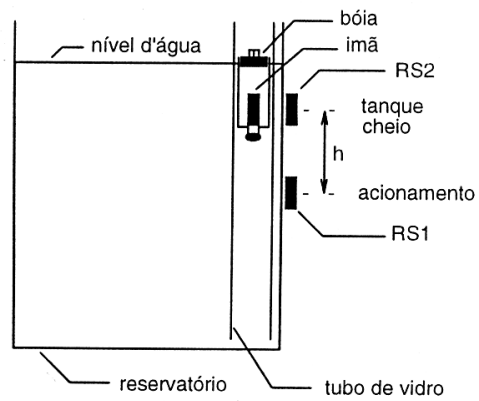

Figura 4. Esquema simplificado do reservatório d'água adaptado.

A bóia foi confeccionada usando uma seringa hipodérmica da marca Plastipak de $3 \mathrm{~mL}$ e de parede fina. As legendas externas de seu corpo foram raspadas para evitar contaminação. As alças foram removidas e o bico da seringa foi fechado por aquecimento para evitar a entrada de água. O êmbolo interno foi cortado de forma a deixar um pequeno pedaço da haste preso à peça de borracha. O imã, vendido como par do reed switch, foi colocado, sem a proteção plástica, no interior da seringa.

$\mathrm{O}$ tubo de vidro possui parede fina e a altura interna do reservatório. Isto porque existe uma distância máxima - que é dada pela soma das espessuras das paredes do reservatório e da seringa e a distância desta até o imã - para que o reed switch seja acionado.

\section{CONTROLE DE VAZÃo dE ÁGUA DE ALIMENTAÇÃO}

Para permitir economia de água, é necessário interromper o fornecimento desta quando o destilador é desligado. Isto é conseguido usando uma válvula de entrada d'água usada em máquinas de lavar roupa (Brastemp), que são do tipo NF, ligada em paralelo com as resistências de aquecimento (figura 3 ). Assim, toda vez que o destilador é acionado, a válvula de entrada é ligada juntamente com as resistências de aquecimento.

Embora tenha sido projetada para operar por curtos intervalos de tempo, a válvula utilizada por nós encontra-se em perfeito funcionamento há vários meses, sendo acionada por ciclos de várias horas.

\section{DISCUSSÃO}

A distância h entre RS1 e RS2 (figura 4) determina o período no qual o destilador funciona. Para valores pequenos de $\mathrm{h}$, o número de vezes que destilador é acionado ao longo do dia deve ser grande. Isto acarreta um consumo maior de energia elétrica e água, pois, em cada uma das vezes, a água da caldeira deve atingir o ponto de ebulição. Por outro lado, caso seja utilizado um valor grande de $\mathrm{h}$, corre-se o risco do reservatório ser esgotado antes que o destilador tenha capacidade de repor seu conteúdo. Esta distância pode ser calculada com base na capacidade de produção de água destilada, consumo médio do laboratório e área de base do reservatório.

Deve-se notar que, caso falte energia elétrica enquanto a bóia estiver nas proximidades ou abaixo de RS1, o destilador só poderá ser acionado manualmente. Aliás, os controles manuais continuam funcionando sempre e o operador pode, a qualquer instante, ligar ou desligar o destilador.

Embora tenha sido construído e utilizado em um conjunto específico de equipamentos, várias adaptações podem ser feitas a fim de adequar a montagem a outras situações. A seguir algumas sugestões são descritas.

Uma grande variedade de destiladores normalmente encontrados nos laboratórios não possuem um CCP como o apresentado, mas sim um interruptor do tipo liga-desliga. Para se utilizar a UCN neste caso, basta substituir esse interruptor por um do tipo chave de partida direta monofásica ou trifásica (chave magnética) da SIEMENS ou similares. Os contatos de RL1 e RL2 devem ser conectados aos dos botões de comando desta chave.

Para evitar acidentes, é necessário colocar disjuntores térmicos em pontos estratégicos do destilador. Esses disjuntores são encontrados no comércio de componentes eletrônicos. No caso do aparelho citado, são utilizados dois destes dispositivos: um colocado no lado externo da caldeira e próximo ao nível d'água e outro na saída do condensador. O primeiro protege contra falta d'água e o segundo, contra a perda de vapor por refrigeração insuficiente.

A UCN não precisa funcionar com a mesma voltagem da rede elétrica do destilador. Com os valores apresentados na figura 2, pode-se operar tanto em 110 como em $220 \mathrm{~V}$. No entanto, o tempo de carga de $\mathrm{C} 1$ será aproximadamente duas vezes maior em 110V. Para reduzir este tempo, basta remover R1 ou trocar R1 e R2 por outros com a metade do valor original.

Os diodos zener Z1 e Z2 podem ser substituídos por qualquer outra combinação que resulte em soma de tensões entre 9,5 e $12 \mathrm{~V}$. É perfeitamente possível utilizar também um único diodo com tensão desta ordem, desde que de mesma potência. Outros valores podem ser utilizados caso os relês RL1 e RL2 sejam substituídos por outros de tensão de acionamento diferente. Uma grande variedade de relês com tensão entre 5 e $24 \mathrm{~V}$, normalmente encontrados no mercado, podem ser utilizados. 